\title{
Current status and future prospects of chemotherapy for advanced hepatocellular carcinoma
}

\author{
Michihisa Moriguchi $^{1} \cdot$ Atsushi Umemura $^{1} \cdot{\text { Yoshito } \text { Itoh }^{1}}^{1}$
}

Received: 1 June 2016/ Accepted: 9 June 2016/Published online: 11 July 2016

(C) Japanese Society of Gastroenterology 2016

\begin{abstract}
Sorafenib is the only drug that demonstrates a survival benefit for advanced hepatocellular carcinoma (HCC). However, the therapeutic effect of sorafenib is limited, so development of a more effective treatment method and second-line treatments is needed. Since the advent of sorafenib, clinical studies have been conducted with a variety of drugs and treatment methods, mainly with molecular targeted therapy, but almost all trials have ended in failure. The reasons for the difficulty in the development of a novel drug or treatment method include the diversity of mechanisms in the carcinogenesis and development of HCC, as well as the presence of background liver diseases such as chronic hepatitis and cirrhosis. Trials with immunecheckpoint inhibitors, which have an entirely different antitumor mechanism from that of molecular targeted drugs or cytotoxic drugs, have recently begun. Based on the results to date, clinical trials are now being conducted with enriched target subjects. In the future, providing more individualized treatment approaches for patients with advanced HCC will be essential.
\end{abstract}

Keywords Hepatocellular carcinoma - Chemotherapy · Molecular targeted therapy - Immune-checkpoint inhibitor · Hepatic arterial infusion chemotherapy

Michihisa Moriguchi

mmori@koto.kpu-m.ac.jp

1 Department of Molecular Gastroenterology and Hepatology, Kyoto Prefectural University of Medicine, Graduate School of Medical Science, 465 Kajii-cho, Kawaramachi-Hirokouji, Kamigyo-ku, Kyoto 602-8566, Japan

\section{Introduction}

Hepatocellular carcinoma (HCC) is the fifth most common cancer in men and the seventh most common cancer in women worldwide, and it is the most common cause of cancer-related death [1]. Many cases of HCC develop from a background of chronic liver diseases such as hepatitis $\mathrm{B}$ virus (HBV) infection, hepatitis $\mathrm{C}$ virus (HCV) infection, alcohol consumption, and non-alcoholic steatohepatitis.

In Japan, HCC surveillance methods are established for $\mathrm{HBV}$ and HCV carriers [2], but there is no surveillance method established for patients with non-HBV and nonHCV (NBNC) hepatitis; thus these cases are sometimes diagnosed only when they progress to severe advanced HCC. In addition, if people do not undergo screening for HBV and HCV infection themselves, the established HCC surveillance system for $\mathrm{HBV}$ and $\mathrm{HCV}$ carriers is rendered ineffective. Such cases are also diagnosed only after progressing to advanced HCC. In these cases, radical therapy comprising hepatectomy or liver transplant cannot be performed [3]. Often, the only choice is palliative treatment with transcatheter arterial chemoembolization (TACE) or systemic chemotherapy.

Even if a radical cure is achieved in HCC, the recurrence rate is high owing to the background liver diseases [4]; thus, the majority of patients eventually end up requiring TACE or systemic chemotherapy.

The efficacy of TACE was ascertained by Llovet et al. [5], and it is now one of the standard treatments for HCC. In addition to Lipiodol-TACE (conventional TACE) [6, 7], which has been used conventionally, recently, drug eluting beads-TACE (DEB-TACE) administered as microspheres have also been used $[8,9]$. The range of available anticancer agents and embolic materials has broadened, which is expected to improve the prognosis of patients with 
advanced HCC. However, this could result in TACE resistance or ineligibility [2] due to a variety of reasons, including reduced efficacy of TACE itself, vascular devastation, involvement of complex extrahepatic blood supply routes, vascular invasion, and distant metastases.

In these instances, sorafenib is the only standard treatment $[10,11]$; however, hepatic function upon initiation of treatment and the limited therapeutic effect are important issues that must be addressed. Furthermore, the lack of secondary therapeutic options is clinically problematic. In Japan, hepatic arterial infusion chemotherapy (HAIC) has been performed since before the advent of sorafenib, and a clinical guideline based on consensus has even placed HAIC as a treatment option for HCC with Vp4 or Vp3 (HCC with tumor progression in the main trunk or the left and right main branches of the portal vein), together with sorafenib [2].

In this review, we will summarize the current status of systemic chemotherapy and HAIC for HCC and the developmental status of novel drugs and therapies.

\section{Systemic chemotherapy}

\section{Sorafenib}

Sorafenib is a drug that suppresses tumor growth by inhibiting serine-threonine kinases Raf-1 and B-Raf, the receptor tyrosine kinase activity of vascular endothelial growth factor receptors (VEGFRs) 1, 2, and 3, and platelet-derived growth factor receptor $\beta$ (PDGFR- $\beta$ ), and by inhibiting tumor cell proliferation and angiogenesis $[12,13]$. The survival benefit of sorafenib, the only standard treatment for $\mathrm{HCC}$, was demonstrated in two global phase III clinical trials, the SHARP trial [10] and the Asia-Pacific study [11] for Child-Pugh A advanced HCC. In subsequent sub-analyses [14], sorafenib was suggested for various tumor situations such as a TACErefractory, macro vascular invasion and extra hepatic metastasis.

\section{Clinical issues with sorafenib}

The efficacy of sorafenib as adjuvant chemotherapy after radical hepatectomy and after radiofrequency ablation has not been demonstrated [15], and while there are ongoing studies investigating a combination of sorafenib and TACE, the efficacy of this treatment has not yet been demonstrated [16, 17] (Table 1). Therefore, the timing of switching from TACE to sorafenib is also clinically problematic. A definition of TACE refractory [2] has been proposed, but in Japan, there are a number of available anticancer drugs and embolic materials; therefore, there are some instances when it is difficult to determine the optimal timing for switching from TACE to sorafenib. In the SHARP trial sub-analyses [14], the hazard ratio of sorafenib against placebo was best in BCLC intermediate stage. When Ogasawara et al. [18] and Arizumi et al. [19] retrospectively compared two groups that satisfied the definition of TACE refractory, one group that continued with TACE and another group that changed to sorafenib, they reported that the sorafenib group had a significantly longer survival period. Therefore, we consider it important to understand the optimal timing for switching to sorafenib. At present, the OPTIMIS trial (NCT01933945) is being deployed globally as a registry trial with the aim of monitoring overall survival (OS) and duration (in days) from the time of TACE non-eligibility to death due to any cause,

Table 1 Clinical trial of sorafenib combined with TACE for intermediate stage HCC

\begin{tabular}{|c|c|c|c|c|}
\hline Trial & Design & Phase & Primary endpoint & \\
\hline SPACE [16] & $\begin{array}{l}\text { TACE + sorafenib vs. TACE + placebo (TACE; DEB/ } \\
\text { scheduled) }\end{array}$ & r-II & $\begin{array}{l}\text { Median TTP } 169 \text { vs. } 166 \text { days } \\
\text { HR } 0.79,95 \% \text { CI } 0.588-1.080 \\
\quad p=0.072\end{array}$ & $*$ \\
\hline Post-TACE [17] & $\begin{array}{l}\text { TACE }+ \text { sorafenib vs. TACE }+ \text { placebo }(\text { TACE; } \\
\text { conventional/1 or } 2 \text { sessions) }\end{array}$ & III & $\begin{array}{l}\text { Median TTP } 5.4 \text { vs. } 3.7 \text { months } \\
\text { HR } 0.87,95 \% \text { CI } 0.70-1.09 \\
\quad p=0.252\end{array}$ & Negative \\
\hline $\begin{array}{l}\text { NCT010004978 } \\
(\text { ECOG1208) }\end{array}$ & $\begin{array}{l}\text { TACE + sorafenib vs. TACE + placebo (TACE; conventional } \\
\text { or DEB/scheduled) }\end{array}$ & III & PFS & Ongoing \\
\hline $\begin{array}{l}\text { NCT01324076 } \\
\text { (TACE-2) }\end{array}$ & $\begin{array}{l}\text { TACE + sorafenib vs. TACE + placebo (TACE; DEB/on } \\
\text { demand) }\end{array}$ & III & PFS & Ongoing \\
\hline $\begin{array}{l}\text { NCT01217034 } \\
\text { (TACTICS) }\end{array}$ & $\begin{array}{l}\text { TACE + sorafenib vs. TACE alone (TACE; conventional/on } \\
\text { demand) }\end{array}$ & II & Time to untreatable progression & Ongoing \\
\hline
\end{tabular}

* The level of significance for the primary endpoint TTP was set at $15 \%$, which was a significant result for sorafenib. However, the period of time until TACE ineligibility was 95 days for sorafenib and 224 days for placebo [HR 1.586 (95 \% CI 1.200-2.096), $p=0.999$ ], and as there was a good result with placebo, the efficacy of the TACE and sorafenib combination therapy was not promising 
and we anticipate that evidence for the appropriate timing of switching will be reported by this trial.

\section{Development status of novel therapeutic drugs and therapeutic methods}

After the advent of sorafenib, there have been various molecular targeted therapies investigated in phase III trials as first-line and second-line therapies. The outcomes and development status of each of the drugs are described below and shown in Table 2.

\section{Molecular targeted therapy}

\section{Brivanib}

Brivanib is a dual tyrosine kinase inhibitor (TKI) of VEGFR and fibroblast growth factor receptors (FGFR). In a phase II trial using brivanib as a first-line drug, median progression-free survival (PFS) was 2.7 months and median OS was 10 months [20]. The phase III BRISK-FL (first-line) trial compared brivanib with sorafenib, and the BRISK-PS (second-line) trial used brivanib for cases of sorafenib non-tolerated or non-responders. In the BRISK-FL trial, the median OS was 9.5 and 9.9 months for brivanib and sorafenib (HR 1.06, $95 \%$ CI $0.93-1.22, p=0.373$ ), respectively, and the study was unable to demonstrate the superiority or noninferiority of brivanib compared to sorafenib [21]. In the BRISK-PS study, the median OS was 9.4 months for brivanib and 8.2 months for placebo (HR $0.89,95 \% \mathrm{CI}$ $0.69-1.15, p=0.331$, which was not a significant difference [22].

\section{Linifanib}

Linifanib is a dual TKI for VEGFR and PDGFR.In a phase II trial, the results were as follows: median PFS, 3.7 months; median OS, 9.7 months [23]. In the LIGHT phase III trial of linifanib as a first-line drug, the median OS was 9.1 months with linifanib and 9.8 months with sorafenib (HR 1.05, $95 \%$ CI 0.90-1.22, NS), which indicated that linifanib was neither superior nor inferior to sorafenib [24]. In addition, several adverse events were

Table 2 Phase 3 trial for advanced HCC

\begin{tabular}{|c|c|c|c|c|}
\hline & Trial & Design & OS (months); HR; $95 \% \mathrm{CI} ; p$ value & \\
\hline \multicolumn{5}{|l|}{ First-line } \\
\hline Brivanib & BRISK-FL [21] & Brivanib vs. sorafenib & $\begin{array}{l}9.5 \text { vs. } 9.9 ; \text { HR } 1.06 ; 95 \% \text { CI } 0.93-1.22 \\
p=0.373\end{array}$ & Negative \\
\hline Linifanib & LIGHT [24] & Linifanib vs. sorafenib & 9.1 vs. $9.8 ; \mathrm{HR} 1.05 ; 95 \%$ CI $0.90-1.22 ; p$ NS & Negative \\
\hline Sunitinib & SUN1170 [25] & Sunitinib vs. sorafenib & $\begin{array}{l}7.9 \text { vs. } 10.2 ; \mathrm{HR} 1.30 ; 95 \% \text { CI } 1.13-1.50 \\
\quad p=0.0014\end{array}$ & Negative \\
\hline Erlotinib & SEARCH [26] & $\begin{array}{l}\text { Erlotinib + sorafenib vs. } \\
\text { placebo + sorafenib }\end{array}$ & $\begin{array}{l}9.5 \text { vs. } 8.5 ; \text { HR } 0.929 ; 95 \% \text { CI } 0.78-1.1 \\
\quad p=0.408\end{array}$ & Negative \\
\hline Lenvatinib & NCT01761266 (E7080) & Lenvatinib vs. sorafenib & $\mathrm{OS}^{\mathrm{a}}$ & Ongoing \\
\hline Nivolumab & NCT02576509 & Nivolumab vs. sorafenib & $\mathrm{TTP}^{\mathrm{a}} \mathrm{OS}^{\mathrm{a}}$ & Ongoing \\
\hline FOLFOX & $\begin{array}{l}\text { NCT00471965 } \\
\text { [33] }\end{array}$ & FOLFOX vs. doxorubicin & $\begin{array}{l}6.5 \text { vs. } 4.9 ; \text { HR } 0.80 ; 95 \% \text { CI } 0.63-1.02 \\
p=0.07\end{array}$ & \\
\hline \multicolumn{5}{|l|}{ Second-line } \\
\hline Brivanib & BRISK-PS [22] & Brivanib vs. placebo & $\begin{array}{l}9.4 \text { vs. } 8.2 ; \text { HR } 0.89 ; 95 \% \text { CI } 0.69-1.15 \\
\quad p=0.331\end{array}$ & Negative \\
\hline Everolimus & EVOLVE-1 [28] & Everolimus vs. placebo & $\begin{array}{l}7.6 \text { vs. } 7.3 ; \mathrm{HR} 1.05 ; 95 \% \text { CI } 0.86-1.27 \text {; } \\
p=0.68\end{array}$ & Negative \\
\hline Cabozantinib & $\begin{array}{l}\text { NCT01908426 } \\
\text { (CELESTIAL) }\end{array}$ & Cabozantinib vs. placebo & $\mathrm{OS}^{\mathrm{a}}$ & Ongoing \\
\hline Ramucirumab & $\begin{array}{l}\text { NCT02435433 (REACH- } \\
\text { II) }\end{array}$ & Ramucirumab vs. placebo & $\mathrm{OS}^{\mathrm{a}}$ & Ongoing \\
\hline Tivantinib & $\begin{array}{l}\text { NCT02029157 } \\
\text { (JET-HCC) }\end{array}$ & Tivantinib vs. placebo & $\mathrm{PFS}^{\mathrm{a}}$ & Ongoing \\
\hline Regorafenib & $\begin{array}{r}\text { NCT01774344 } \\
\text { (RESORCE) }\end{array}$ & Regorafenib vs. placebo & $\mathrm{OS}^{\mathrm{a}}$ & $\#$ \\
\hline TS-1 & S-CUBE [34] & TS-1 vs. placebo & $\begin{array}{l}11.25 \text { vs. } 11.33 ; \text { HR } 0.86 ; 95 \% \text { CI } 0.67-1.10 \\
p=0.220\end{array}$ & Negative \\
\hline
\end{tabular}

a The primary endpoint

\# A press release has reported that this trial has met its primary endpoint 
recorded in the linifanib group, including hypertension and hepatic encephalopathy.

\section{Sunitinib}

Sunitinib is a multikinase inhibitor that broadly inhibits VEGFR, PDGFR, and c-kit, but the phase III trial (SUN1170 trial) conducted as a first-line trial had to be discontinued early owing to the potent toxicity of sunitinib. The median OS with sunitinib was 7.9 months compared with 10.2 months for sorafenib (HR 1.30, $95 \%$ CI $1.13-1.50, p=0.0014$ ) [25].

\section{Erlotinib}

Erlotinib is an epidermal growth factor receptor (EGFR)related tyrosine kinase enzyme inhibitor, and a randomized controlled trial with sorafenib + erlotinib versus sorafenib was conducted as a first-line phase III trial (SEARCH trial) for advanced HCC. The median OS in the combination group was 9.5 months and in the sorafenib group was 8.5 months; therefore, the superiority of this combination could not be demonstrated (HR 0.929, $95 \%$ CI 0.78-1.1, $p=0.408)$. Potent toxicity was observed in the combination group [26].

\section{Lenvatinib}

Lenvatinib is a multi-TKI for VEGFR1-3, FGFR1-4, PDGFR $\alpha$, and is rearranged during transfection (RET). Phase I and II trials were conducted for Child-Pugh A advanced HCC resistant to standard treatment. The response rate was $34.8 \%$ and the median OS was 18.3 months (95\% CI 12.8-), which is an extremely promising result [27]. A phase III trial of first-line treatment (E7080) is currently underway.

\section{Everolimus}

Everolimus is a mammalian target of rapamycin (mTOR) inhibitor. In a phase III trial (EVOLVE-1) conducted as second-line treatment, the median OS with everolimus was 7.6 months compared to 7.3 months with placebo (HR 1.05, $95 \%$ CI $0.86-1.27, p=0.68)$; thus, a superiority in terms of survival was not demonstrated against placebo [28].

\section{Cabozantinib}

Cabozantinib is a multi-kinase inhibitor that inhibits MET, VEGFR-2, and RET. A phase II trial was conducted for patients with advanced HCC with a history of systemic chemotherapy, and the median PFS was 4.2 months, which is a good outcome [29]. A phase III trial (CELESTIAL) of cabozantinib as a second-line treatment is currently underway.

\section{Ramucirumab}

Ramucirumab is a recombinant $\operatorname{IgG} 1$ monoclonal antibody that has a high affinity for specifically binding with the extracellular domain of VEGFR-2. In a phase III trial (REACH study) as a second-line treatment for advanced HCC, the median OS was 7.6 months in the placebo group compared to 9.2 months in the ramucirumab group (HR $0.87,95 \%$ CI $0.72-1.05, p=0.14)$; thus, the efficacy of the treatment was not demonstrated [30]. However, in the sub-analysis, the efficacy of ramucirumab in patients with alpha-fetoprotein (AFP) levels $>400 \mathrm{ng} / \mathrm{ml}$ was promising; therefore, a phase III trial (REACH-2) is underway for the AFP $>400 \mathrm{ng} / \mathrm{ml}$ population.

\section{Tivantinib}

Tivantinib is a selective c-MET inhibitor, and in a phase II trial as a second line treatment, time to progression (TTP) was 1.6 months in the tivantinib group and 1.4 months in the placebo group (HR 0.64, $95 \%$ CI 0.43-0.94, $p=0.04$ ). In the sub-analysis evaluation with immunostaining, however, the results were tivantinib group 2.7 months, placebo group 1.4 months (HR 0.43, $95 \%$ CI 0.19-0.97, $p=0.03$ ) in cases diagnosed with high expression of c-MET [31], suggesting efficacy. Because of this result, a phase III trial (JETHCC) of tivantinib as a second line treatment only for groups with high c-MET expression is underway.

\section{Regorafenib}

Regorafenib is a multikinase inhibitor that targets VEGFR1-3, c-kit, RET, BRAF, PDGFR, and FGFR. In phase II trials targeting patients previously treated with sorafenib, the median OS was 13.8 months $(95 \% \mathrm{CI}$ 9.3-18.3), which indicates a good outcome [32]. Based on these results, a phase III trial (RESORCE) is underway with regorafenib as a second-line treatment. Just recently, a press release has reported that this trial has met its primary endpoint of improving OS (http://press.bayer.com/baynews/ baynews.nsf/id/Phase-III-Trial-Regorafenib-Patients-Unre sectable-Liver-Cancer-Meets-Primary-EndpointImproving? OpenDocument\&sessionID=1462393761).

\section{Cytotoxic chemotherapy}

\section{FOLFOX versus doxorubicin}

This trial was conducted in Asia as a first-line treatment, but the overall response rate with FOLFOX was 8.2 and 
$2.7 \%$ with doxorubicin. The median OS was 6.40 months with FOLFOX and 4.97 months with doxorubicin (HR $0.80,95 \%$ CI $0.63-1.02, p=0.07$ ); thus, a significant difference was not observed, but a subsequent post hoc analysis suggested a statistical significance $(p=0.04)$ [33]. Conducting a phase III trial with sorafenib seems to be difficult, but in the future, FOLFOX may be an option for sorafenib non-responders.

\section{TS-1}

In a phase III trial (S-CUBE) with a second-line setting, superiority over placebo in terms of survival was not demonstrated [34], but the results suggest the possibility of more specific populations gaining more benefit with TS-1 [35].

The results of almost all of the trials were disappointing for the presented drugs, but the reasons for this include problems such as low response rates, adverse events, and differences in background liver diseases. The response rate in the current ongoing lenvatinib phase II trial [27] is comparatively high, and it has promising results. However, based on the findings from previous clinical trials, such as those with tivantinib and ramucirumab, phase III trials with enriched targets are underway.

\section{Immune-checkpoint inhibitors}

Recently, the efficacy of programmed cell death 1 (antiPD-1) antibodies, cytotoxic T-lymphocyte-associated protein 4 antibodies, and others, against malignant tumors has been reported [36-38].

Studies of tumor immunity in $\mathrm{HCC}$ have reported a correlation between the high expression PD-L1 and tumor progression and prognosis [39], and researchers have also shown a correlation between the presence of $\mathrm{CD} 3+\mathrm{CD} 8+$ $\mathrm{T}$ cell lymphocytes in tumor tissue and recurrence-free survival [40]. A phase I clinical trial with nivolumab has been completed, and there have been responsive cases [41], so there are high expectations of clinical applications. There is currently a global phase III (NCT02576509) trial underway.

\section{Hepatic arterial infusion chemotherapy}

Typical examples of agents used for HAIC include IAcall $^{\circledR}$ (Nihon Kayaku, Japan) one-shot intra-arterial injection [42], low-dose 5-fluorouracil and cisplatin (LFP) repeated intra-arterial injection with a reservoir catheter system [43, 44], and 5-fluorouracil continuous intra-arterial injection with a reservoir catheter system in combination with subcutaneous interferon administration (5FU/IFN) $[45,46]$. The results of phase II trials with IA-call ${ }^{\circledR}$ oneshot intra-arterial injection reported a response rate of $33.8 \%$ [42]. Recently, in the sorafenib + IA-call versus sorafenib phase II trial (HCC_Sor_CDDP_rP2) a potentiated effect of HR 0.74 is anticipated with IA-call [47] (Table 3). A phase III trial has been planned.

Slight variability was observed in LFP and 5FU/IFN regimens, but both treatments were reported to have a higher tumor reduction effect than sorafenib $[10,11,43-46]$. While their efficacy has not been demonstrated in prospective studies, in Japan these regimens are often used as an option for advanced HCC. Several reports have revealed that both regimens could also achieve tolerable outcomes for HCC with Vp3 or Vp4, which are known to be poor prognostic factors [43-46]; therefore, HAIC is listed with sorafenib in the consensus guideline [2], and in some cases is used as first-line treatment. Unfortunately, in the recently implemented SILIUS trial (sorafenib alone vs. sorafenib + LFP) LFP had no potentiating effect on sorafenib; however, in the subanalysis, the efficacy of LFP was suggested in Vp4 cases [48] (Table 3).

\section{Future prospects}

Many trials for the development of new treatments for advanced HCC, particularly centered on molecular targeted therapy, have flourished since the advent of sorafenib, but the results to date have been extremely disappointing except for that of regorafenib treatment. Treatment development for HCC is more difficult than for other solid tumors, possibly because of the high diversity in the

Table 3 Clinical trial on HAIC combined with sorafenib therapy for advanced HCC

\begin{tabular}{|c|c|c|c|c|}
\hline $\begin{array}{l}\text { HAIC } \\
\text { regimen }\end{array}$ & Trial & Design & Phase & Median OS (months), HR (95\% CI) \\
\hline IA-call & $\begin{array}{l}\text { NCT010004978 (HCC_Sor_CDDP_rP2) } \\
\text { [47] }\end{array}$ & $\begin{array}{l}\text { Sorafenib + IA-call vs. } \\
\text { sorafenib }\end{array}$ & II & 9.5 vs. $7.0,0.74$ \\
\hline LFP & NCT01324076 (SILIUS) [48] & Sorafenib + LFP vs. LFP & III & 11.8 vs. $11.8,1.0(0.7-1.4)$ \\
\hline
\end{tabular}


specific mechanisms involved in the carcinogenesis and development of HCC, as well as the presence of chronic liver diseases in the background. Even with extremely promising drugs, there are many instances where the drugs had to be abandoned part way through development due to potent adverse events.

Recently, clinical trials have commenced with immunecheckpoint inhibitors for HCC, and their clinical development is moving to the next step. In the future, however, it would be preferable to progress with development of enriched trials in populations where a high degree of anticancer effect is expected, based on the results of previous clinical trials, while bearing in mind the liver diseases in the background. There is a demand for more individualized treatment for advanced HCC.

\section{Compliance with ethical standards}

Conflict of interest Itoh $\mathrm{Y}$ received a research grant from Esai Co., Ltd. and Bristol Myers Inc. Moriguchi $\mathrm{M}$ and Umemura A declare that they have no conflict of interest.

\section{References}

1. Torre LA, Bray F, Siegel RL, Ferlay J, Lortet-Tieulent J, Jemal A. Global cancer statistics, 2012. CA Cancer J Clin. 2015;65:87-108.

2. Kudo M, Matsui O, Izumi N, Liver Cancer Study Group of Japan, et al. JSH consensus-based clinical practice guidelines for the management of hepatocellular carcinoma: 2014 update by the Liver Cancer Study Group of Japan. Liver Cancer. 2014;2014(3):458-68.

3. Belghiti J, Fuks D. Liver resection and transplantation in hepatocellular carcinoma. Liver Cancer. 2012;1:71-82.

4. Bruix J, Llovet JM. Prognostic prediction and treatment strategy in hepatocellular carcinoma. Hepatology. 2002;35:519-24.

5. Llovet JM, Real MI, Montaña X, Barcelona Liver Cancer Group, et al. Arterial embolisation or chemoembolisation versus symptomatic treatment in patients with unresectable hepatocellular carcinoma: a randomised controlled trial. Lancet. 2002;359:1734-9.

6. Takayasu K, Arii S, Kudo M, et al. Superselective transarterial chemoembolization for hepatocellular carcinoma. Validation of treatment algorithm proposed by Japanese guidelines. J Hepatol. 2012;56:886-92.

7. Ikeda M, Arai Y, Park SJ, Japan Interventional Radiology in Oncology Study Group (JIVROSG), Korea Interventional Radiology in Oncology Study Group (KIVROSG), et al. Prospective study of transcatheter arterial chemoembolization for unresectable hepatocellular carcinoma: an Asian cooperative study between Japan and Korea. J Vasc Interv Radiol. 2013;24:490-500.

8. Lammer J, Malagari K, Vogl T, PRECISIONV Investigators, et al. Prospective randomized study of doxorubicin-eluting-bead embolization in the treatment of hepatocellular carcinoma: results of the PRECISIONV study. Cardiovasc Interv Radiol. 2010;33:41-52.

9. Golfieri R, Giampalma E, Renzulli M, PRECISION ITALIA STUDY GROUP, et al. Randomised controlled trial of doxorubicin-eluting beads vs conventional chemoembolisation for hepatocellular carcinoma. Br J Cancer. 2014;111:255-64.

10. Llovet JM, Ricci S, Mazzaferro V, SHARP Investigators Study Group, et al. Sorafenib in advanced hepatocellular carcinoma. N Engl J Med. 2008;359:378-90.

11. Cheng AL, Kang YK, Chen Z, et al. Efficacy and safety of sorafenib in patients in the Asia-Pacific region with advanced hepatocellular carcinoma: a phase III randomised, double-blind, placebo-controlled trial. Lancet Oncol. 2009;10:25-34.

12. Wilhelm SM, Carter C, Tang L, et al. BAY 43-9006 exhibits broad spectrum oral antitumor activity and targets the RAF/MEK/ ERK pathway and receptor tyrosine kinases involved in tumor progression and angiogenesis. Cancer Res. 2004;64:7099-109.

13. Chang YS, Adnane J, Trail PA, et al. Sorafenib (BAY 43-9006) inhibits tumor growth and vascularization and induces tumor apoptosis and hypoxia in RCC xenograft models. Cancer Chemother Pharmacol. 2007;59:561-74.

14. Raoul JL, Bruix J, Greten TF, et al. Relationship between baseline hepatic status and outcome, and effect of sorafenib on liver function: SHARP trial subanalyses. J Hepatol. 2012;56:1080-8.

15. Bruix J, Takayama T, Mazzaferro V, STORM Investigators, et al. Adjuvant sorafenib for hepatocellular carcinoma after resection or ablation (STORM): a phase 3, randomised, double-blind, placebo-controlled trial. Lancet Oncol. 2015;16:1344-54.

16. Lencioni R, Llovet JM, Han G, et al. Sorafenib or placebo plus TACE with doxorubicin-eluting beads for intermediate stage HCC: the SPACE trial. J Hepatol. 2016;64:1090-8.

17. Kudo M, Imanaka K, Chida N, et al. Phase III study of sorafenib after transarterial chemoembolisation in Japanese and Korean patients with unresectable hepatocellular carcinoma. Eur J Cancer. 2011;47:2117-27.

18. Ogasawara S, Chiba T, Ooka Y, et al. Efficacy of sorafenib in intermediate-stage hepatocellular carcinoma patients refractory to transarterial chemoembolization. Oncology. 2014;87:330-41.

19. Arizumi T, Ueshima K, Minami T, et al. Effectiveness of sorafenib in patients with transcatheter arterial chemoembolization (TACE) refractory and intermediate-stage hepatocellular carcinoma. Liver Cancer. 2015;4:253-62.

20. Park JW, Finn RS, Kim JS, et al. Phase II, open-label study of brivanib as first-line therapy in patients with advanced hepatocellular carcinoma. Clin Cancer Res. 2011;17:1973-83.

21. Johnson PJ, Qin S, Park JW, et al. Brivanib versus sorafenib as first-line therapy in patients with unresectable, advanced hepatocellular carcinoma: results from the randomized phase III BRISK-FL study. J Clin Oncol. 2013;31:3517-24.

22. Llovet JM, Decaens T, Raoul JL, et al. Brivanib in patients with advanced hepatocellular carcinoma who were intolerant to sorafenib or for whom sorafenib failed: results from the randomized phase III BRISK-PS study. J Clin Oncol. 2013;31:3509-16.

23. Toh HC, Chen PJ, Carr BI, et al. Phase 2 trial of linifanib (ABT869 ) in patients with unresectable or metastatic hepatocellular carcinoma. Cancer. 2013;119:380-7.

24. Cainap C, Qin S, Huang WT, et al. Linifanib versus sorafenib in patients with advanced hepatocellular carcinoma: results of a randomized phase III trial. J Clin Oncol. 2015;33:172-9.

25. Cheng AL, Kang YK, Lin DY, et al. Sunitinib versus sorafenib in advanced hepatocellular cancer: results of a randomized phase III trial. J Clin Oncol. 2013;31:4067-75.

26. Zhu AX, Rosmorduc O, Evans TR, Ross PJ, Santoro A, Carrilho FJ, et al. SEARCH: a phase III, randomized, double-blind, placebo-controlled trial of sorafenib plus erlotinib in patients with advanced hepatocellular carcinoma. J Clin Oncol. 2015;33:559-66.

27. Ikeda K, Kumada H, Kudo M, et al. Phase I/II trial of lenvatinib (E7080), a multi-targeted tyrosine kinase inhibitor, in patients 
(pts) with advanced hepatocellular carcinoma (HCC). Ann Oncol. 2012;23(Suppl 9; abstr 737P).

28. Zhu AX, Kudo M, Assenat E, et al. Effect of everolimus on survival in advanced hepatocellular carcinoma after failure of sorafenib: the EVOLVE-1 randomized clinical trial. JAMA. 2014;312:57-67.

29. Verslype C, Cohn AL, Kelley RK, et al. Activity of cabozantinib (XL184) in hepatocellular carcinoma: Results from a phase II randomized discontinuation trial (RDT). J Clin Oncol. 2012;30(Suppl; abstr 4007).

30. Zhu AX, Park JO, Ryoo BY, REACH Trial Investigators, et al. Ramucirumab versus placebo as second-line treatment in patients with advanced hepatocellular carcinoma following first-line therapy with sorafenib (REACH): a randomised, double-blind, multicentre, phase 3 trial. Lancet Oncol. 2015;16:859-70.

31. Santoro A, Rimassa L, Borbath I, et al. Tivantinib for second-line treatment of advanced hepatocellular carcinoma: a randomised, placebo-controlled phase2 study. Lancet Oncol. 2013;14:55-63.

32. Bruix J, Tak WY, Gasbarrini A, et al. Regorafenib as second-line therapy for intermediate or advanced hepatocellular carcinoma: multicentre, open-label, phase II safety study. Eur J Cancer. 2013;49:3412-9.

33. Qin S, Bai Y, Lim HY, et al. Randomized, multicenter, openlabel study of oxaliplatin plus fluorouracil/leucovorin versus doxorubicin as palliative chemotherapy in patients with advanced hepatocellular carcinoma from Asia. J Clin Oncol. 2013;31:3501-8.

34. Kudo M, Moriguchi M, Numata K, et al. A randomized, doubleblind, placebo-controlled phase III study of S-1 in patients with sorafenib-refractory advanced hepatocellular carcinoma (SCUBE). J Clin Oncol. 2015; 33(Suppl; abstr 4018).

35. Kudo M, Okusaka T, Kaneko S, et al. Identification of a highresponse patient population to $S-1$ via predictive enrichment strategy analysis of the S-CUBE phase III trial. J Clin Oncol. 2016; 34(Suppl 4S; abstr 229).

36. Topalian SL, Hodi FS, Brahmer JR, et al. Safety, activity, and immune correlates of anti-PD-1 antibody in cancer. $\mathrm{N}$ Engl J Med. 2012;366:2443-54.

37. Larkin J, Chiarion-Sileni V, Gonzalez R, et al. Combined nivolumab and ipilimumab or monotherapy in untreated melanoma. N Engl J Med. 2015;373:23-34.

38. Borghaei H, Paz-Ares L, Horn L, et al. nivolumab versus docetaxel in advanced nonsquamous non-small-cell lung cancer. N Engl J Med. 2015;373:1627-39.
39. Gao Q, Wang XY, Qiu SJ, et al. Overexpression of PD-L1 significantly associates with tumor aggressiveness and postoperative recurrence in human hepatocellular carcinoma. Clin Cancer Res. 2009;15:971-9.

40. Gabrielson A, Wu Y, Wang H, et al. Intratumoral CD3 and CD8 T-cell densities associated with relapse-free survival in HCC. Cancer Immunol Res. 2016;4:419-30.

41. El-Khoueiry AB, Melero I, Crocenzi TS, et al. Phase I/II safety and antitumor activity of nivolumab in patients with advanced hepatocellular carcinoma (HCC): CA209-040. J Clin Oncol. 2015; 33(Suppl; abstr LBA101).

42. Yoshikawa M, Ono N, Yodono H, Ichida T, Nakamura H. Phase II study of hepatic arterial infusion of a fine-powder formulation of cisplatin for advanced hepatocellular carcinoma. Hepatol Res. 2008;38:474-83.

43. Ando E, Tanaka M, Yamashita F, et al. Hepatic arterial infusion chemotherapy for advanced hepatocellular carcinoma with portal vein tumor thrombosis: analysis of 48 cases. Cancer. 2002;95:588-95.

44. Ueshima K, Kudo M, Takita M, et al. Hepatic arterial infusion chemotherapy using low-dose 5-fluorouracil and cisplatin for advanced hepatocellular carcinoma. Oncology. 2010;78:148-53.

45. Yamashita T, Arai K, Sunagozaka H, et al. Randomized, phase II study comparing interferon combined with hepatic arterial infusion of fluorouracil plus cisplatin and fluorouracil alone in patients with advanced hepatocellular carcinoma. Oncology. 2011;81:281-90.

46. Obi S, Yoshida H, Toune R, et al. Combination therapy of intraarterial 5-fluorouracil and systemic interferon-alpha for advanced hepatocellular carcinoma with portal venous invasion. Cancer. 2006;106:1990-7.

47. Ikeda M, Shimizu S, Sato T, et al. Sorafenib plus intra-arterial cisplatin versus sorafenib alone in patients with advanced hepatocellular carcinoma: a randomized phase II trial. J Clin Oncol. 2015; 33(Suppl; abstr 4076).

48. Kudo M, Ueshima K, Yokosuka O, et al. Prospective randomized controlled phase III trial comparing the efficacy of sorafenib versus sorafenib in combination with low-dose cisplatin/fluorouracil hepatic arterial infusion chemotherapy in patients with advanced hepatocellular carcinoma. J Hepatol. 2016;64(Suppl 2; abstr LB04). 